\title{
Production of biodiesel from mixed waste vegetable oils using Ferric hydrogen sulphate as an effective reusable heterogeneous solid acid catalyst.
}

\begin{abstract}
Biodiesel production by simultaneous esterification and transesterification of waste oil with methanol has been studied in a heterogeneous system using solid ferric hydrogen sulphate [Fe (HSO4)3] acid catalyst. The catalyst was prepared by displacement reaction followed by calcination at $400{ }^{\circ} \mathrm{C}$ for $3 \mathrm{~h}$. The prepared catalyst was characterized using X-ray diffraction (XRD), Fourier transform infrared spectrometer (FT-IR), Brunner-Emmett-Teller surface area measurement (BET), thermal gravimetric analyzer (TGA) and temperature-programmed desorption of NH3 (TPD - NH3). Furthermore, the dependence of the conversion of mixed waste oil on the reactions variables such as the molar ratio of methanol/oil, the amount of catalysts used, reaction temperatures, reusability were also investigated. The catalyst was reused many times with slight loss in activity and the maximum yield of $94.5 \%$ was achieved at the optimized conditions of reaction temperature of $205^{\circ} \mathrm{C}$; stirring speed of $350 \mathrm{rpm}, 1: 15$ molar ratio of oil to alcohol and $1 \% \mathrm{w} / \mathrm{w}$ catalyst loading.
\end{abstract}

Keyword: Biodiesel; Ferric hydrogen sulphate; Esterification; Transesterification; Mixed waste vegetable oil; Reusable 